\title{
A Simple Analytical Method for High-Throughput Screening of Major Sugars from Soybean by Normal-Phase HPLC with Evaporative Light Scattering Detection
}

\author{
Babu Valliyodan, Haiying Shi, and Henry T. Nguyen \\ National Center for Soybean Biotechnology and Division of Plant Sciences, University of Missouri, Columbia, MO 65211, USA \\ Correspondence should be addressed to Henry T. Nguyen; nguyenhenry@missouri.edu
}

Received 26 March 2015; Accepted 16 June 2015

Academic Editor: Masami Shibukawa

Copyright (C) 2015 Babu Valliyodan et al. This is an open access article distributed under the Creative Commons Attribution License, which permits unrestricted use, distribution, and reproduction in any medium, provided the original work is properly cited.

\begin{abstract}
This paper presents a simple analytical method for determining sugars in soybean (Glycine max (L.) Merr.) tissues. Sample preparation was modified from several early published methods. High-performance liquid chromatography (HPLC) equipped with an evaporative light scattering detector (ELSD) was used to separate, identify, and quantify seven sugars, including glucose, galactose, fructose, sucrose, melibiose, raffinose, and stachyose. Two mobile phases were programed into a gradient elution. Mobile phase $A$ is pure water and mobile phase $B$ is a mixture of acetonitrile and acetone $75: 25(\mathrm{v} / \mathrm{v})$. Total chromatographic retention time is less than 20 minutes. This method has been validated for detection limit, calibration range, and intraday and interday repeatability. This method has been used analyzing more than 5000 soybean samples in the experiments studying natural genetic variation of sugar contents and components in soybean seeds and other tissues.
\end{abstract}

\section{Introduction}

Soybeans are naturally enriched with oil, protein, and carbohydrates. In food industries, soybeans are processed to several consumable soya products, such as soy milk, tofu, miso, soy sauce, natto, and soy meals. Soybeans are also important constituent of animal feeds. Flavors and nutritive values of soya foods are greatly affected by sugar contents of soybeans. Major sugar components in soybean are fructose, glucose, sucrose, raffinose, and stachyose. Fructose and glucose are monosaccharide, while sucrose is a disaccharide and these three sugars are easily digestible. Raffinose and stachyose are trisaccharide and tetrasaccharide, respectively, and belong to raffinose family oligosaccharides (RFOs). Human and other monogastric animals are not able to digest RFOs due to lack of an enzyme called alpha-galactosidase in their small intestine [1-3]. This allows RFOs to move to the lower gut where they act as substrate for fermentation by gut microbes and increase the flatulence inducing gases such as $\mathrm{CO}_{2}, \mathrm{CH}_{4}$, and $\mathrm{H}_{2} \mathrm{~S}$ causing abdominal discomfort and diarrhea $[4,5]$. It has been reported that removal of RFOs from soybean meal results in a large increase in the metabolizable energy for chickens.
These adverse effects such as flatulence and poor digestibility can severely limit the use of soybean in animal, including human, diets. All these studies suggest that the production of soybeans with low levels of RFOs and higher levels of sucrose is desirable for its enhanced food and feed qualities.

Sugar analysis has been primarily carried out by high performance liquid chromatography (HPLC) because of simplicity, accuracy, and separation ability. Chromatographic separation is achieved by appropriate combination of stationary phase and mobile phase. Stationary phases or HPLC columns for separating sugars are mainly categorized in three types with regard to packing materials: ligand exchange, normal phase, and anion-exchange. Mobile phases are prepared solutions that facilitate separation of sugars when they carry a sample through a column. Ligand-exchange columns are backboned with sulfonated polystyrene carrying a metal counter ion, such as calcium ions or sodium ions. They are environment friendly because of the use of pure water as the mobile phase [6] and are generally used for separating mono- and disaccharides. In the case of a normal phase, the packing material is silica gel or a polymer bonded with amino groups. Solutions of mixed water and acetonitrile 
are normally used as the mobile phase [7]. Normal phase can be used for separating sugars from a complex matrix. Anion-exchange columns are packed with polymeric resin attached with quaternary ammonium and such columns have to incorporate with a strong basic mobile phase $(\mathrm{pH}>12)$ in sugar analysis.

Preferred chromatographic detection of sugars includes refractive index, UV-visible, fluoresce, pulsed amperometric detector, mass spectrometry, and evaporative light scattering. Refractive index (RI) detector has been used for analyzing oligosaccharides from soybean since the 70's [8] and it is still a popular detector in soybean sugar analyses $[9,10]$. Nevertheless, sensitivity and selectivity of this detector are poor. Due to the lack of chromophore at mid-UV wavelengths, carbohydrates are only detectable by UV-visible detector at the deeper UV range of $190 \mathrm{~nm}-195 \mathrm{~nm}$. At such short wavelengths, interference from mobile phase is inevitable since most of the solvents absorb strongly as well. To enhance UV absorption of carbohydrate, some researchers resorted to sample derivatization [11-13]. Such sample treatment complicated the analytical procedures and contributed to preventable assay variability. Pulsed amperometric detector coupled with anion exchange column (HPAEC-PAD) is one of the popular HPLC systems for carbohydrate analysis due to its better sensitivity and selectivity [14-17]. However, reliability of HPAEC-PAD is dependent on the chemical purity of the mobile phase. The HPAEC-PAD requires high alkaline $(\mathrm{pH}>12)$ mobile phase. Dissolved carbon dioxide from the atmosphere, or carbonate contamination of mobile phase, reduces column retaining power as a result of the buildup of interfering anions in the stationary phase. A common problem of the above detectors is baseline drifting with gradient elution. Popularity of evaporative light scattering detection (ELSD) is fast growing in chemical and biochemical analysis. In the past decade ELSD has been widely utilized for analyzing lipids and carbohydrates in plants, fruits, beverages, milks, and several other different tissues and organisms [18-25]. The principle of evaporating solvents prior to detection employed in the ELSD resolves baseline shifting and therefore enhances baseline stability and response intensity.

Sample preparation is an important step in method development for soybean and other plants. The procedure normally consists of sample extraction and sample purification. In some studies, soybean flour or powder was first defatted using hexane or other appropriate solvents. The defatted samples were then refluxed in ethanol aqueous solutions at elevated temperatures for a certain length of time [26, 27]. Giannoccaro et al. reported that water extracts sugars most efficiently from the nondefatted soybeans [28]. The extract solution was then purified with an organic solvent, such as acetonitrile or ethanol, to remove soluble proteins [14, 29].

In this paper we report a simplified method to analyze sugars from soybean. Sample preparation was successively conducted in the same sample vial. It overcame long and elaborate procedures engaged in early methods, such as to separate soybean tissues from the extract, to allocate, to dry, and to redissolve the extracted solution. The HPLC conditions of this method were optimized for high chromatographic resolution and short run time. Addition of $25 \%$ acetone to acetonitrile mobile phase was found critical to improve separation of galactose from its adjacent epimer glucose. This method is highly useful for screening large scale soybean populations in genetic and breeding programs for crop improvement with value-added traits.

\section{Materials and Methods}

2.1. Materials and HPLC System. Sugar standards, Dfructose, D-(+) galactose, D-(+) glucose, sucrose, D- $(+)$ melibiose, $\mathrm{D}-(+)$ raffinose pentahydrate, and stachyose hydrate, were purchased from Sigma Aldrich (St Louis, MO, U.S.A). HPLC grade of acetonitrile, acetone, and water were purchased from Fisher Scientific (Hampton, NH, U.S.A). Compressed nitrogen of ultrahigh-purity (UHP) grade was purchased from Praxair (Danbury, CT, U.S.A). The HPLC-ELSD system was Agilent 1200 series (Agilent, U.S.A). The Prevail Carbohydrate ES columns, $5 \mu 250 \mathrm{~mm} \times 4.6 \mathrm{~mm}$, and guard columns, $7.5 \times 4.6 \mathrm{~mm}$, were from Grace Davison Discovery Sciences (Deerfield, IL, U.S.A). Soybean seeds were harvested from the Bradford Research Farm, Columbia, Missouri, and Delta Research Center, Portageville, Missouri.

2.2. Sample and Standard Preparation. Approximately one gram of soybean seeds was ground using Thomas Wiley Mini-Mill fitted with 20-mesh screen. The ground powder was lyophilized for two days in a Labconco Freeze Dry System (Labconco, U.S.A.). Dried soybean powder of 90.25 $( \pm 0.25) \mathrm{mg}$ was weighed and mixed with $900 \mu \mathrm{L}$ HPLC-grade water in $2 \mathrm{~mL}$ centrifuge vials. The vials were incubated at $55^{\circ} \mathrm{C}$ with $250 \mathrm{rpm}$ agitation for 30 minutes followed by 30 -second high speed vortex. After cooling down to room temperature, $900 \mu \mathrm{L}$ HPLC grade acetonitrile was blended in. The suspension was centrifuged for 30 minutes at $13.3 \times$ $1000 \mathrm{~min}^{-1} \times \mathrm{g}$. The supernatant was further diluted five times with acetonitrile: water mixture of $65: 35(\mathrm{v} / \mathrm{v})$ before being subjected to HPLC analysis. Sugar standards were prepared in water with concentrations of 50, 100, 200, 300, 400, 500, and $1000 \mu \mathrm{g} / \mathrm{mL}$.

2.3. HPLC Analysis. Two kinds of mobile phase were prepared: mobile phase A was pure water, and mobile phase B was acetonitrile: acetone mixture of $75: 25(\mathrm{v} / \mathrm{v})$. Flow rate and gradient of phases A and B (Table 1) were optimized for complete separation of the sugars in the shortest run time. Column temperature was maintained at $35^{\circ} \mathrm{C}$ throughout the gradient program. Detector temperature was isothermal at $55^{\circ} \mathrm{C}$. Nebulizer pressure was 3.4 bar. Ultrapurity-grade nitrogen (grade 5.0) was used as the nebulizer gas. Sample injection volume was $5 \mu \mathrm{L}$.

\section{Results and Discussion}

3.1. Sample Preparation. Soybean is known for high protein. A substantial amount of protein concurrently dissolves in water during extraction. Purification of the extract is therefore very important to eliminate matrix interference from the dissolved proteins. Protein was commonly precipitated with 
95\% or pure acetonitrile. Earlier methods required four to seven steps to conduct purification, which included preparation of $95 \%$ acetonitrile, separation of suspended sugar solution from soybean tissues, transferring a given volume of supernatant to a new tube, blending in acetonitrile, removing protein, drying, and redissolving sugars. Our method requires only two steps, that is, directly adding pure acetonitrile to the same sample vial after the completion of extraction and removing soybean tissue and precipitated proteins simultaneously. This modified method effectively eliminates process variables as less preparation steps were involved.

Dilution is another key factor in this method. Low concentration of sugars is desirable not only for optimum peak shape and separation but also for an extended column life cycle. However, abundance of different sugars varies greatly in soybean; for example, Hou et al. showed that soybean is composed of $0.07-0.15 \%$ glucose, $0.08-0.19 \%$ fructose, $5.6-$ 9.4\% sucrose, $0.3-1.4 \%$ raffinose, and $0.3-6 \%$ stachyose [30]. After taking consideration of all possible impacts, we set the dilution factor as 10 , that is, solvent-to-sample ratio of $10: 1$ $(\mathrm{mg} / \mathrm{mL})$.

3.2. Chromatographic Separation. The HPLC mobile phase plays a crucial role in sugar separation. Addition of acetone to acetonitrile mobile phase differentiates this method from other published methods. As shown in Figure 1, acetone effectively improves peak resolution without additional elution time. Figures 1(a) and 1(b) represent chromatograms obtained from mobile phases with and without acetone. The acetone with a portion of $20 \%$ to $30 \%$ in acetonitrile was capable of resolving galactose and glucose isomers although galactose was under the detection limit (very low concentrations) in most of the soybean seeds. The $10 \%$ window of acetone concentration in mobile phase makes this method robust. The elution gradient was accomplished with the mixed solvents of acetone and acetonitrile (25/75) and water. Emergence of all sugars occurred before 14 minutes. Six more minutes were programmed to stabilize the system. At retention time of 14.1 minutes, the flow rate was promptly reduced to $0.2 \mathrm{~mL} / \mathrm{min}$ from $1.2 \mathrm{~mL} / \mathrm{min}$, and meanwhile the mobile phase ratio of $\mathrm{A}$ and $\mathrm{B}$ was changed to $20: 80$ from $50: 50$ (see Table 1 ). This gradient change allows the system to reach its initial stage without causing high column back pressure.

3.3. Identification and Quantification. Each sugar component was recognized by its distinctive retention time. Commercial references were used for confirmation. Under the chromatographic conditions described in Section 2, sugars eluted in the order of fructose, galactose, glucose, sucrose, melibiose, raffinose, and stachyose as shown in Figure 2.

Figure 3 represents three types of sugar distribution of soybean germplasm seeds. Figure 3(a) is from a soybean germplasm that has multiple sugars and each sugar has a significant amount. Figure 3(b) indicates that sucrose and stachyose are predominant components in another soybean germplasm line. The chromatogram (Figure 3(c)) is from a different soybean germplasm and this sugar profile is most desirable for animal feed uses. This germplasm line with high

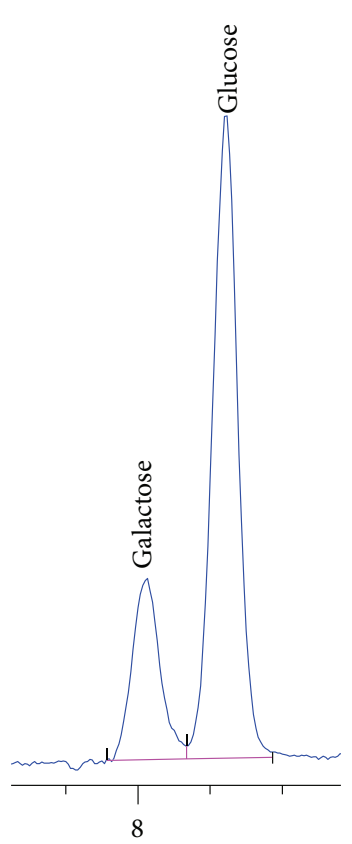

(a)

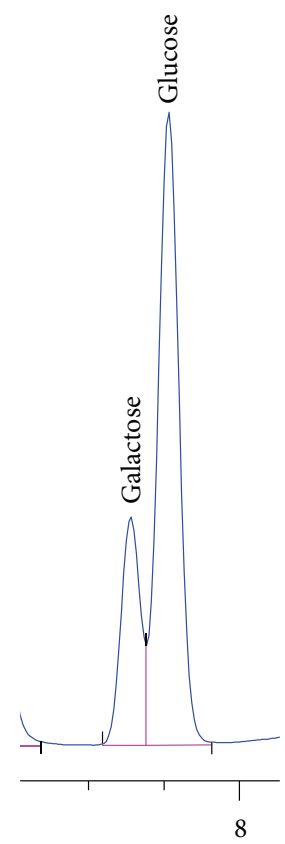

(b)
Figure 1: Chromatograms obtained from (a) acetone in mobile phase; (b) no acetone in mobile phase.

TABLE 1: Gradient-elution of mobile phases.

\begin{tabular}{lcc}
\hline Time (minutes) & $\mathrm{A}: \mathrm{B}$ & Flow rate $(\mathrm{mL} / \mathrm{min})$ \\
\hline 0 & $20: 80$ & 1.2 \\
5 & $20: 80$ & 1.2 \\
12 & $50: 50$ & 1.2 \\
14 & $50: 50$ & 1.2 \\
14.1 & $20: 80$ & 0.2 \\
20 & $20: 80$ & 1.2 \\
\hline
\end{tabular}

sucrose, low raffinose, and low stachyose was discovered after screening more than 1000 germplasm lines (Plant Introductions) obtained from the USDA seed bank (USDAGRIN) and grown in the University of Missouri (MU) research fields. During all of the germplasm screenings, galactose was least abundant and not detectable in most of the soybean lines. Trace amount of melibiose was detected only in few soybean lines.

Quantification of the sugars was accomplished by calibration curves that ranged from 50 to $1000 \mu \mathrm{g} / \mathrm{mL}$ (Figures 4(a) and 4(b)). Fundamentally, an ELSD responds to concentration change in a nonlinear fashion. The relationship between measured peak area or peak height and sample concentrations is reflected by a 2 nd-order polynomial equation, as shown below:

$$
\mathbf{A}=\mathbf{a} \mathbf{X}^{2}
$$

where $\mathbf{A}$ is peak area (or peak height), a is quadratic coefficient, and $\mathbf{X}$ is sample concentration. To correct the quadratic effect, a mathematical model [31-33] is usually used, such as $\log \mathbf{A}=\mathbf{a}^{\prime}+\mathbf{2} \log \mathbf{X}$. We found a solid linear 


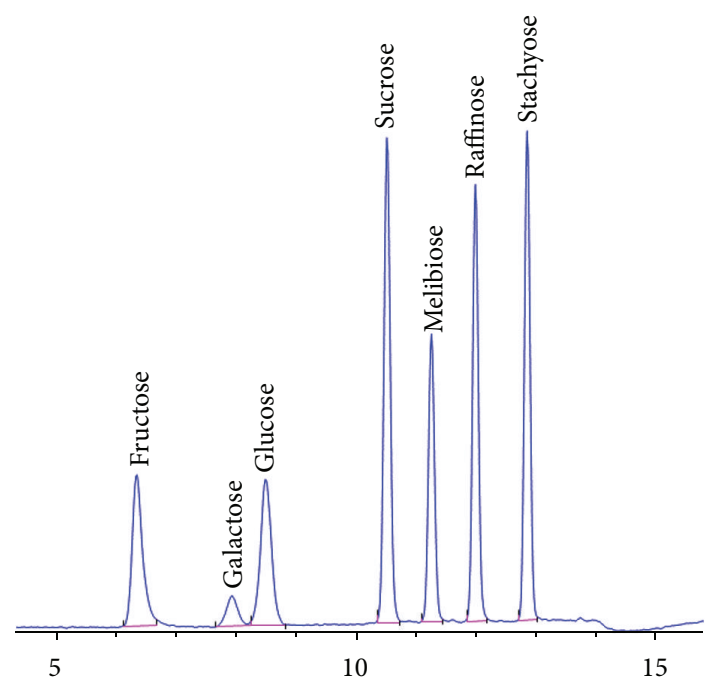

FIGURE 2: Chromatogram of sugar standards (concentration of each sugar is $300 \mu \mathrm{g} / \mathrm{mL}$ ).

regression after logarithmic conversion in the specified range of 50 to $1000 \mu \mathrm{g} / \mathrm{mL}$ except for galactose which is slightly narrowed down to the range of 200 to $1000 \mu \mathrm{g} / \mathrm{mL}$. Correlation coefficient $R^{2}$ values of all sugars were greater than 0.99 . This model allows us to perform quantification directly from (1) without applying other conversion or mathematical models.

3.4. Method Validation: Spike Recovery Rate, Detection Limit, and Precision Test. Recovery rate of each sugar was obtained by spiking known amount of standards at different steps of sample preparation. In one of the spiking experiments, standards were added to the dried soybean samples. In another experiment spike standards were added to the sugar extracts. In both cases, $500 \mu \mathrm{g} / \mathrm{mL}$ of each sugar standard was spiked. Each experiment was repeated four times. The recovery result was shown in Table 2. Most of the spiked standards were recovered close to $100 \%$. Detection limit (DL) of each individual sugar was calculated based on the formula below:

$$
\text { Detection limit }(\mu \mathrm{g} / \mathrm{mL})=\frac{50}{\mathrm{~S} / \mathrm{N}} \times 3 \text {, }
$$

where 50 is the concentration of standard in the unit of $\mu \mathrm{g} / \mathrm{mL}$ used for DL determination, and $\mathrm{S} / \mathrm{N}$ is the ratio of signal over noise produced from the $50 \mu \mathrm{g} / \mathrm{mL}$ standard.

Relative standard deviation (RSD\%) of both interday and intraday was determined and reported in Table 2. Intraday variation was less than $3 \%$ and interday variation was less than $10 \%$, except for melibiose that is at a trace level and therefore detected with a higher variation.

Accuracy of the method was further evaluated on an HPAEC-PAD system from an external lab. Six finely ground and dried soybean seed samples were verified by the HPAECPAD for sucrose, raffinose, and stachyose. Table 3 shows that the results are close from one method to the other, except that raffinose in sample- 1 and sample- 5 is not detectable by HPAEC-PAD. Note that each data in Table 3 is an average

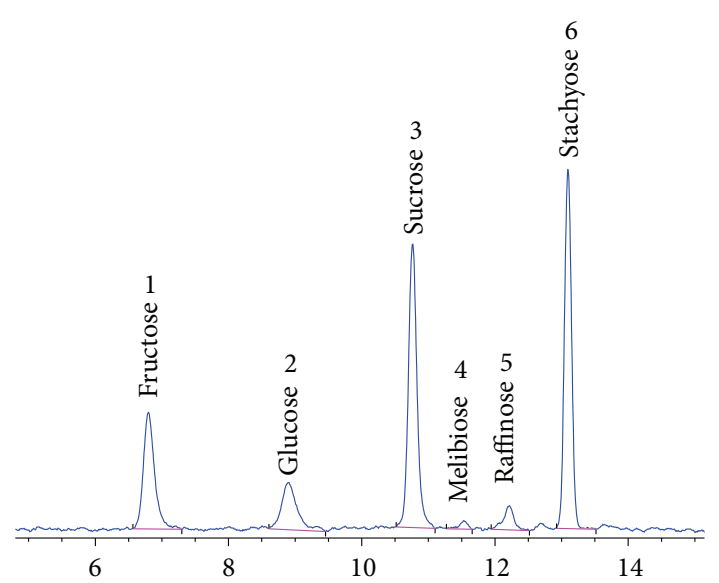

(a)

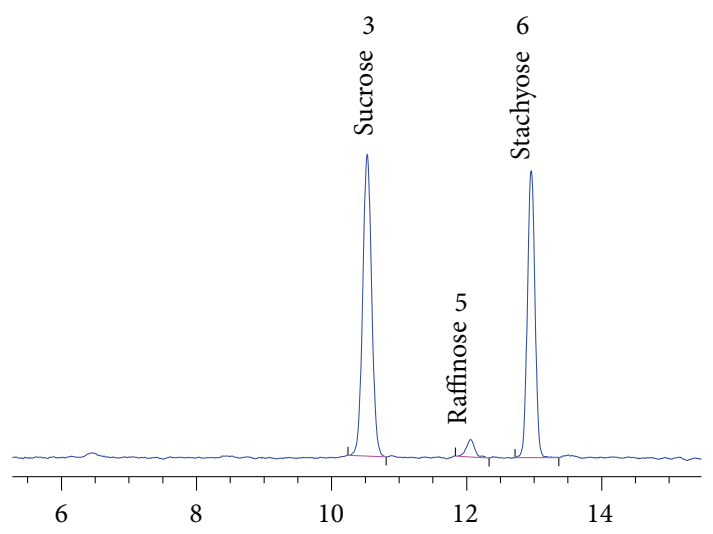

(b)

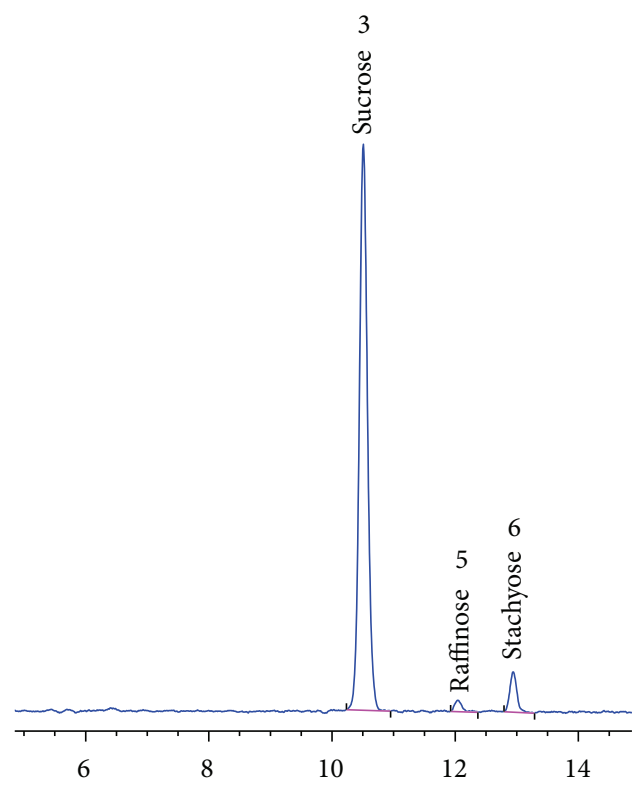

(c)

Figure 3: Distribution of sugars in different soybean germplasm lines. 


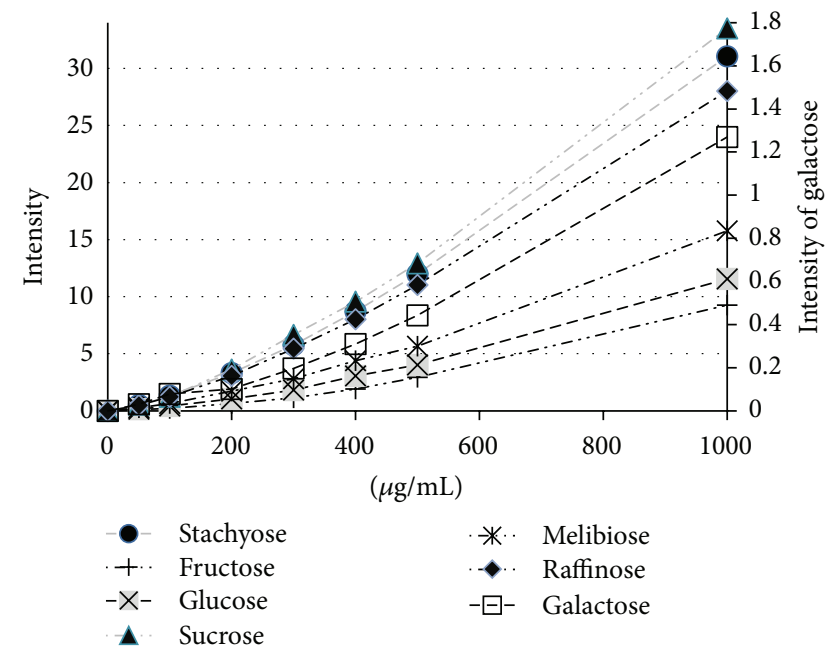

(a)

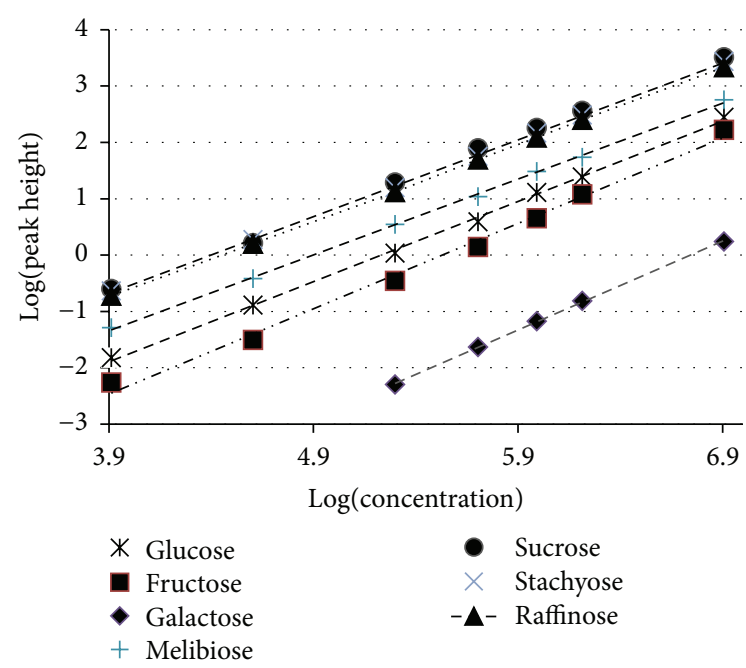

(b)

FIGURE 4: Calibration curves of seven sugars. (a) Quadratic regression; (b) $\log$ (peak intensity)/ $\log ($ standard concentration) linear expression.

TABLE 2: Method validation including detection limit, repeatability and spike recovery.

\begin{tabular}{|c|c|c|c|c|c|}
\hline & \multirow{3}{*}{$\begin{array}{l}\text { Detection limit } \\
\text { ppm }\end{array}$} & \multicolumn{2}{|c|}{ Repeatability } & \multicolumn{2}{|c|}{ Recovery $(\%) \pm$ RSD } \\
\hline & & $\begin{array}{l}\text { Intraday } \\
\text { (RSD\%) }\end{array}$ & $\begin{array}{l}\text { Interday } \\
\text { (RSD\%) }\end{array}$ & $\begin{array}{l}\text { Spike to dried } \\
\text { sample }\end{array}$ & $\begin{array}{l}\text { Spike to } \\
\text { sugar extract }\end{array}$ \\
\hline & & $(n=6)$ & $(n=6)$ & $(n=4)$ & $(n=4)$ \\
\hline Fructose & 60.0 & 2.2 & 6.0 & $103 \pm 1.5$ & $101 \pm 2.0$ \\
\hline Galactose & 135.0 & - & - & $105 \pm 3.2$ & $111 \pm 1.2$ \\
\hline Glucose & 30.0 & 2.0 & 9.0 & $101 \pm 1.1$ & $99 \pm 1.0$ \\
\hline Sucrose & 9.3 & 1.2 & 2.9 & $99 \pm 3.0$ & $98 \pm 4.4$ \\
\hline Melibiose & 19.4 & 1.7 & 12.0 & $73 \pm 1.4$ & $92 \pm 0.5$ \\
\hline Raffinose & 12.1 & 1.7 & 2.9 & $102 \pm 2.8$ & $101 \pm 1.6$ \\
\hline Stachyose & 10.0 & 1.2 & 4.7 & $102 \pm 0.9$ & $102 \pm 3.9$ \\
\hline
\end{tabular}

value of three replicates. Sample-1 and sample-5 have been frequently used in our lab as daily controls to monitor analysis variations. Their values have been consistently obtained as $0.8 \%$ and $0.6 \%$, respectively. The present method evidently demonstrated high sensitivity.

3.5. Application of the Method. This analytical method has played a significant role in the research projects on the natural genetic variation of sugar contents and components in soybean seeds and other tissues conducted at the University of Missouri. The soy industry and soy food markets need soybeans with high-sucrose, low-raffinose, and stachyose content and with low trypsin inhibitor activity as one package. This will provide high levels of energy and yield better tasting food and feed without inducing indigestion problems. The extensive screening of soybean plant introductions (PIs) and current soybean varieties for natural genetic variation will help identifying new sources for gene discovery and further application in molecular breeding and crop improvement programs. More than 5000 lines have been screened. Several soybean PIs with low raffinose and stachyose and high sucrose in seed tissues have been identified. Table 4 shows the minimum and maximum levels of major sugar components after a statistical analysis of 540 soybean germplasm lines with maturity groups III and IV. These maturity groups are highly suitable for Missouri and other US soybean production areas. Total sugars varied from 56.7 to $160.3 \mathrm{mg} / \mathrm{g}$ that was equivalent to $5.7 \%$ to $16.0 \%$ of dry matter. For an example, Figure 5 shows the distribution of sucrose content in the selected soybean germplasm lines. A few lines with as high as 9-10\% sucrose were selected after screening around 1500 lines for crossing and population development for gene discovery.

\section{Conclusion}

Developing an HPLC method that can resolve a mixture of mono-, di-, tri-, and oligosaccharides in a short elution time is a challenge. Earlier described methods had several shortcomings and some of the methods have shown an unacceptable long retention time for raffinose and stachyose while some others had poor resolution or broad peaks. The method presented in this paper is simple, fast, reliable, and 
TABLE 3: Comparison of sugar content generated from the present method with the HPAEC-PAD method.

\begin{tabular}{|c|c|c|c|c|c|c|}
\hline & $\begin{array}{l}\text { Present } \\
\text { method }\end{array}$ & $\begin{array}{l}\text { HPAEC- } \\
\text { PAD }\end{array}$ & $\begin{array}{l}\text { Present } \\
\text { method }\end{array}$ & $\begin{array}{l}\text { HPAEC- } \\
\text { PAD }\end{array}$ & $\begin{array}{l}\text { Present } \\
\text { method }\end{array}$ & $\begin{array}{l}\text { HPAEC- } \\
\text { PAD }\end{array}$ \\
\hline & \multicolumn{2}{|c|}{$\begin{array}{c}\text { Sucrose\% (dry matter) } \\
(n=3)\end{array}$} & \multicolumn{2}{|c|}{$\begin{array}{c}\text { Stachyose\% (dry matter) } \\
(n=3)\end{array}$} & \multicolumn{2}{|c|}{$\begin{array}{c}\text { Raffinose\% (dry matter) } \\
(n=3)\end{array}$} \\
\hline Sample-1 & 7.1 & 6.8 & 0.9 & 0.5 & 0.8 & - \\
\hline Sample-2 & 5.8 & 4.8 & 3.5 & 3.1 & 0.6 & 0.3 \\
\hline Sample-3 & 4.7 & 3.4 & 4.3 & 3.2 & 0.6 & 0.3 \\
\hline Sample-4 & 2.8 & 2.1 & 3.7 & 2.6 & 1.1 & 0.9 \\
\hline Sample-5 & 5.7 & 4.2 & 1.4 & 1.0 & 0.6 & - \\
\hline Sample-6 & 3.1 & 2.1 & 4.4 & 3.2 & 0.9 & 0.5 \\
\hline
\end{tabular}

TABLE 4: Maximum and minimum sugar component concentration in the 540 soybean germplasm lines.

\begin{tabular}{lccccccc}
\hline & Fructose & Glucose & $\begin{array}{c}\text { Sucrose } \\
\text { (sugar content in soybean } \mathrm{mg} / \mathrm{g} \text { (dry matter) })\end{array}$ & $\begin{array}{c}\text { Melibiose } \\
\text { Maximum }\end{array}$ & \multicolumn{2}{c}{ Stachyose } & Total sugar \\
Minimum & 2.1 & 13.7 & 73.4 & 7.7 & 33.4 & 70.9 & 160.3 \\
Average & 8.1 & - & 15.0 & - & 3.4 & 3.2 & 56.7 \\
\hline
\end{tabular}

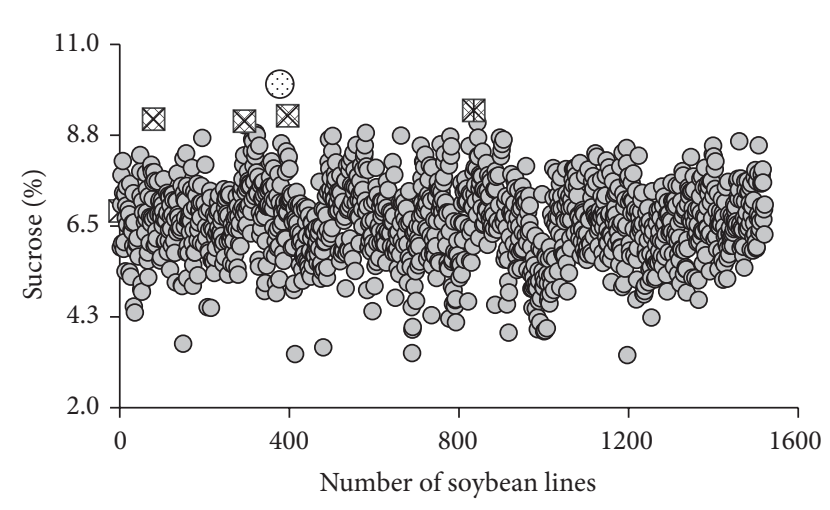

FIGURE 5: Distribution of sucrose contents in the seeds of 1500 soybean germplasm.

successful in the case of high throughput screening. The HPLC of this method is comprised of a column, specially packed for carbohydrate assay and equipped with an ELSD detector. The mobile phase is $25 \%$ acetone in acetonitrile and water. All major sugars in soybean, that is, fructose, glucose, sucrose, raffinose, and stachyose, are completely resolved in less than 14 minutes. Sample preparation procedure is much simplified and improved from known methods. The optimal low sample-to-solvent ratio $(10 \mathrm{mg}: 1 \mathrm{~mL})$ lessened sample load and extended HPLC column life. More than 1500 samples can be analyzed on a single HPLC column. The detection limit in this method is low; for example, sucrose is $9.3 \mathrm{ppm}$ and others are lower than $60 \mathrm{ppm}$. The selection of calibration range allows direct quantification from the nonlinear detector output. Robustness and high throughput application of this method help soybeans breeding programs including the one for developing soybean varieties with reduced RFOs and higher metabolizable energy.

\author{
Abbreviations \\ RFO: $\quad$ Raffinose family oligosaccharides \\ HPLC: $\quad$ High performance liquid chromatography \\ UV: $\quad$ Ultraviolet \\ RI: $\quad$ Refractive index \\ HPAEC-PAD: High-performance anion-exchange \\ chromatography with pulsed \\ amperometric detection \\ ELSD: $\quad$ Evaporative light scattering detector \\ PI: Plant introduction.
}

\section{Conflict of Interests}

The authors declare that there is no conflict of interests regarding the publication of this paper.

\section{Acknowledgments}

This study was supported by the United Soybean Board, Grant no. 1236. The authors acknowledge Dr. Grover J. Shannon for soybean germplasm seed increase at the Delta Research Center, University of Missouri, Portageville, Missouri, and Dr. Tri D. Vuong, Department of Plant Science, University of Missouri, for helping collection of more than 5000 data using this method.

\section{References}

[1] J. J. Rackis, "Oligosaccharides of food legumes: alphagalactosidase activity and flatulence problem," in Physilogical Effects of Food Carbohydrates, A. Jeanes and J. Hodge, Eds., pp. 207-222, American Chemical Society, Washington, DC, USA, 1975.

[2] F. L. Suarez, J. Springfield, J. K. Furne, T. T. Lohrmann, P. S. Kerr, and M. D. Levitt, "Gas production in humans ingesting 
a soybean flour derived from beans naturally low in oligosaccharides," American Journal of Clinical Nutrition, vol. 69, no. 1 , pp. 135-139, 1999.

[3] J. D. Neus, W. R. Fehr, and S. R. Schnebly, "Agronomic and seed characteristics of soybean with reduced raffinose and stachyose," Crop Science, vol. 45, no. 2, pp. 589-592, 2005.

[4] V. Kumar, A. Rani, L. Goyal et al., "Sucrose and raffinose family oligosaccharides (RFOs) in soybean seeds as influenced by genotype and growing location," Journal of Agricultural and Food Chemistry, vol. 58, no. 8, pp. 5081-5085, 2010.

[5] K. B. Hagely, D. Palmquist, and K. D. Bilyeu, "Classification of distinct seed carbohydrate profiles in soybean," Journal of Agricultural and Food Chemistry, vol. 61, no. 5, pp. 1105-1111, 2013.

[6] H. F. Walton, "Ligand-exchange chromatography: a brief review," Industrial and Engineering Chemistry Research, vol. 34, no. 8, pp. 2553-2554, 1995.

[7] C. M. Montera, M. C. R. Dodero, D. A. G. Sánchez, and C. G. Barroso, "Analysis of low molecular weight carbohydrates in food and beverages: a review, Chromatographia, vol. 59, no. 1-2, pp. 15-30, 2004.

[8] L. T. Black and E. B. Bagley, "Determination of oligosaccharides in soybeans by high pressure liquid chromatography using an internal standard," Journal of the American Oil Chemists' Society, vol. 55, no. 2, pp. 228-232, 1978.

[9] J. L. Chávez-Servín, A. I. Castellote, and M. C. López-Sabater, "Analysis of mono- and disaccharides in milk-based formulae by high-performance liquid chromatography with refractive index detection," Journal of Chromatography A, vol. 1043, no. 2, pp. 211-215, 2004.

[10] J. C. M. Barreira, J. A. Pereira, M. B. P. P. Oliveira, and I. C. F. R. Ferreira, "Sugars profiles of different chestnut (Castanea sativa Mill.) and almond (Prunus dulcis) cultivars by HPLC-RI," Plant Foods for Human Nutrition, vol. 65, no. 1, pp. 38-43, 2010.

[11] F. N. Lamari, R. Kuhn, and N. K. Karamanos, "Derivatization of carbohydrates for chromatographic, electrophoretic and mass spectrometric structure analysis," Journal of Chromatography B: Analytical Technologies in the Biomedical and Life Sciences, vol. 793, no. 1, pp. 15-36, 2003.

[12] H. K. Joung, H. Huang, W. K. Gyoung, and J. C. Won, "Simultaneous quantitative determination of monosaccharides including fructose in hydrolysates of yogurt and orange juice products by derivatization of monosaccharides with $\mathrm{p}$-aminobenzoic acid ethyl ester followed by HPLC," Bulletin of the Korean Chemical Society, vol. 26, no. 10, pp. 1533-1538, 2005.

[13] R. Masuda, K. Kaneko, and I. Yamashita, "Sugar and cyclitol determination in vegetables by HPLC using postcolumn fluorescent derivatization," Journal of Food Science, vol. 61, no. 6, pp. 1186-1190, 1996.

[14] A. Hou, P. Chen, A. Shi, B. Zhang, and Y.-J. Wang, "Sugar variation in soybean seed assessed with a rapid extraction and quantification method," International Journal of Agronomy, vol. 2009, Article ID 484571, 8 pages, 2009.

[15] S. Ouchemoukh, P. Schweitzer, M. B. Bey, H. Djoudad-Kadji, and H. Louaileche, "HPLC sugar profiles of Algerian honeys," Food Chemistry, vol. 121, no. 2, pp. 561-568, 2010.

[16] W. Widmer, "Analysis of biomass sugars and galacturonic acid by gradient anion exchange chromatography and pulsed amperometric detection without post-column addition," Biotechnology Letters, vol. 33, no. 2, pp. 365-368, 2011.

[17] C. Corradini, A. Cavazza, and C. Bignardi, "High-performance anion-exchange chromatography coupled with pulsed electrochemical detection as a powerful tool to evaluate carbohydrates of food interest: principles and applications," International Journal of Carbohydrate Chemistry, vol. 2012, Article ID 487564, 13 pages, 2012.

[18] C. Ma, Z. Sun, C. Chen, L. Zhang, and S. Zhu, "Simultaneous separation and determination of fructose, sorbitol, glucose and sucrose in fruits by HPLC-ELSD," Food Chemistry, vol. 145, pp. 784-788, 2014.

[19] P. Shanmugavelan, S. Y. Kim, J. B. Kim et al., "Evaluation of sugar content and composition in commonly consumed Korean vegetables, fruits, cereals, seed plants, and leaves by HPLCELSD," Carbohydrate Research, vol. 380, pp. 112-117, 2013.

[20] X. Liu, N. Ai, H. Zhang et al., "Quantification of glucose, xylose, arabinose, furfural, and HMF in corncob hydrolysate by HPLCPDA-ELSD," Carbohydrate Research, vol. 353, pp. 111-114, 2012.

[21] U. Sharma, P. Bhandari, N. Kumar, and B. Singh, "Simultaneous determination of ten sugars in Tinospora cordifolia by ultrasonic assisted extraction and LC-ELSD," Chromatographia, vol. 71, no. 7-8, pp. 633-638, 2010.

[22] F. A. Agblevor, B. R. Hames, D. Schell, and H. L. Chum, "Analysis of biomass sugars using a novel HPLC method," Applied Biochemistry and Biotechnology, vol. 136, no. 3, pp. 309326, 2007.

[23] R. Slimestad and I. M. Vågen, “Thermal stability of glucose and other sugar aldoses in normal phase high performance liquid chromatography," Journal of Chromatography A, vol. 1118, no. 2, pp. 281-284, 2006.

[24] K. Downes and L. A. Terry, "A new acetonitrile-free mobile phase method for LC-ELSD quantification of fructooligosaccharides in onion (Allium cepa L.)," Talanta, vol. 82, no. 1, pp. 118-124, 2010.

[25] R. Slimestad, R. Seljaasen, K. Meijer, and S. L. Skar, "Norwegiangrown Jerusalem artichoke (Helianthus tuberosus L.): morphology and content of sugars and fructo-oligosaccharides in stems and tubers," Journal of the Science of Food and Agriculture, vol. 90, no. 6, pp. 956-964, 2010.

[26] E. M. Bainy, S. M. Tosh, M. Corredig, V. Poysa, and L. Woodrow, "Varietal differences of carbohydrates in defatted soybean flour and soy protein isolate by-products," Carbohydrate Polymers, vol. 72, no. 4, pp. 664-672, 2008.

[27] T. M. Kuo, J. F. vanMiddlesworth, and W. J. Wolf, "Content of raffinose oligosaccharides and sucrose in various plant seeds," Journal of Agricultural and Food Chemistry, vol. 36, no. 1, pp. 32-36, 1988.

[28] E. Giannoccaro, Y.-J. Wang, and P. Chen, "Effects of solvent, temperature, time, solvent-to-sample ratio, sample size, and defatting on the extraction of soluble sugars in soybean," Journal of Food Science, vol. 71, no. 1, pp. C59-C64, 2006.

[29] Y. Lv, X. B. Yang, Y. Zhao, Y. Ruan, Y. Yang, and Z. Z. Wang, "Separation and quantification of component monosaccharides of the tea polysaccharides from Gynostemma pentaphyllum by HPLC with indirect UV detection," Food Chemistry, vol. 112, no. 3, pp. 742-746, 2009.

[30] A. Hou, P. Chen, J. Alloatti et al., "Genetic variability of seed sugar content in worldwide soybean germplasm collections," Crop Science, vol. 49, no. 3, pp. 903-912, 2009.

[31] L. Fang, M. Wan, M. Pennacchio, and J. Pan, "Evaluation of evaporative light-scattering detector for combinatorial library quantitation by reversed phase HPLC," Journal of Combinatorial Chemistry, vol. 2, no. 3, pp. 254-257, 2000.

[32] S. Man, W. Gao, Y. Zhang et al., "Qualitative and quantitative determination of major saponins in Paris and Trillium by 
HPLC-ELSD and HPLC-MS/MS," Journal of Chromatography B, vol. 878, no. 29, pp. 2943-2948, 2010.

[33] Y. Tang, W. Jiang, Q. Wu et al., "Comparative characteristic of the inflammatory diterpenes in the roots of Euphorbia fischeriana with different preparation method using HPLC-ELSD," Fitoterapia, vol. 83, no. 3, pp. 427-433, 2012. 

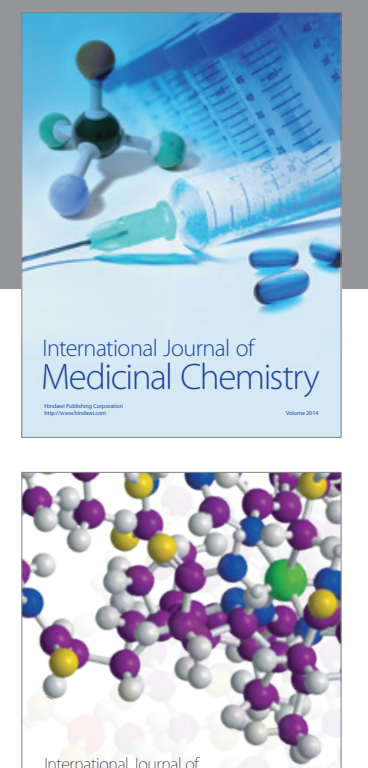

\section{Carbohydrate} Chemistry

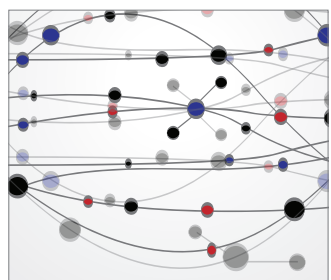

The Scientific World Journal
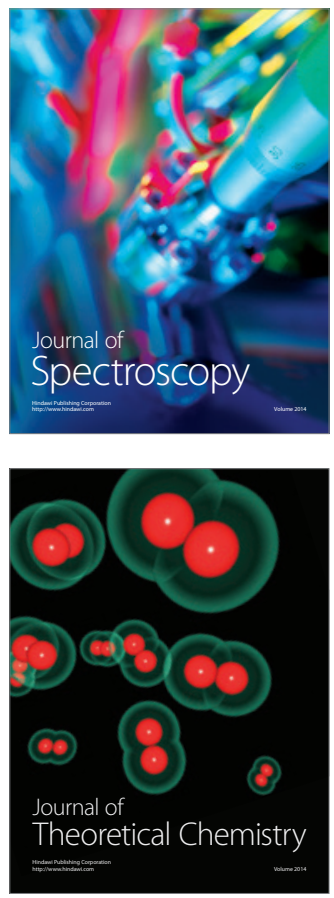
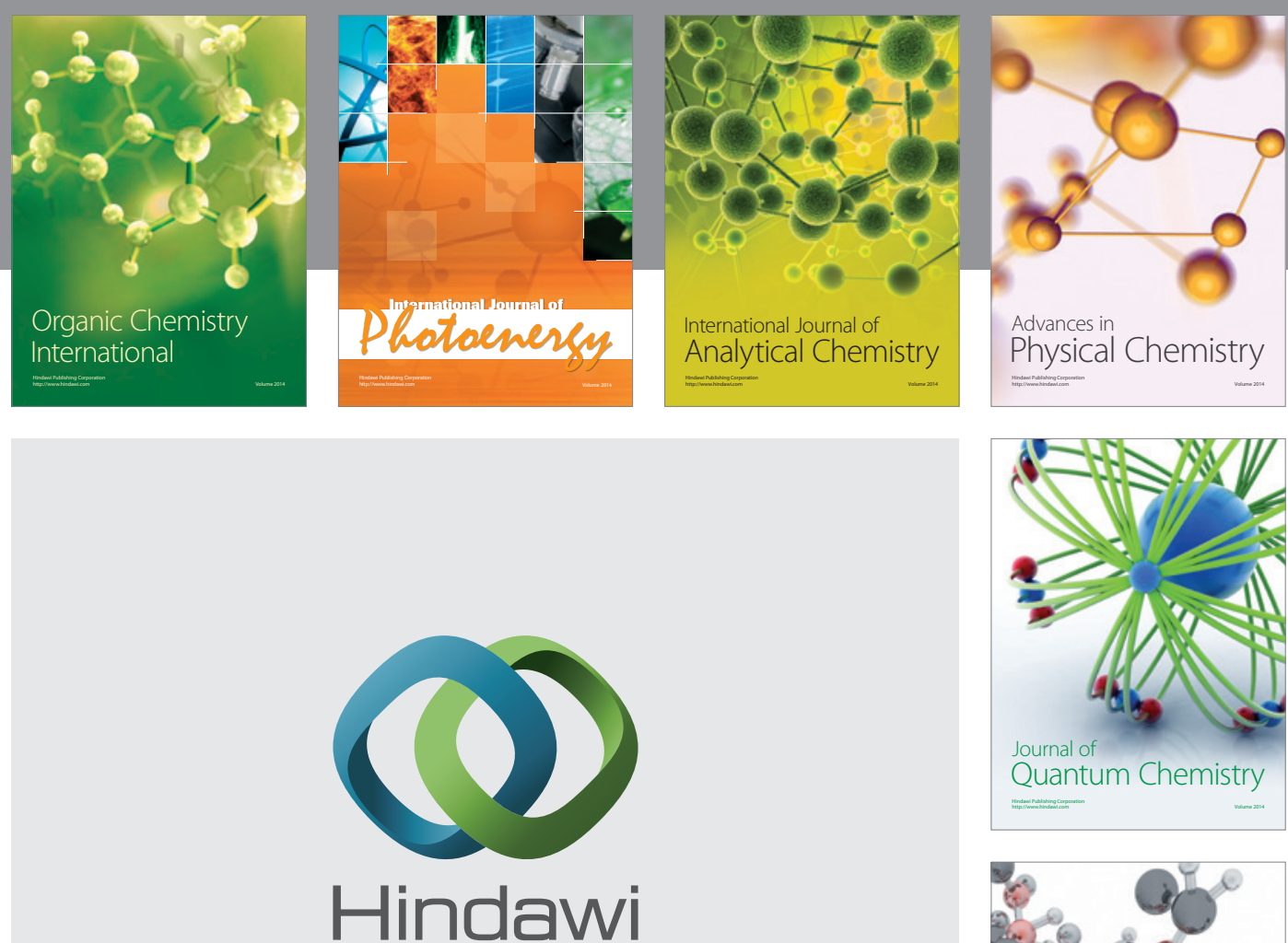

Submit your manuscripts at

http://www.hindawi.com

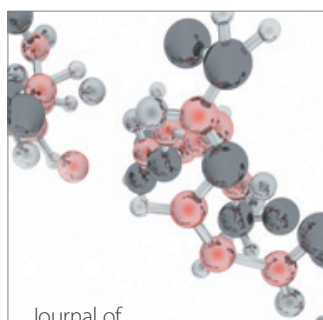

Analytical Methods

in Chemistry

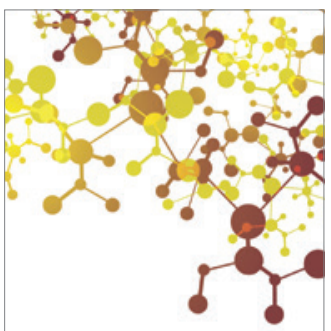

Journal of

Applied Chemistry

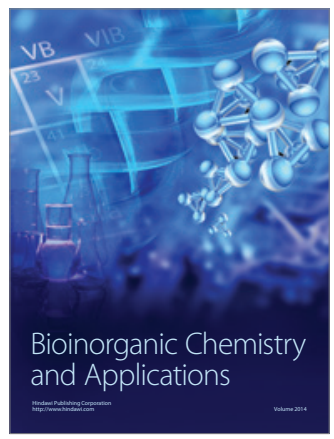

Inorganic Chemistry
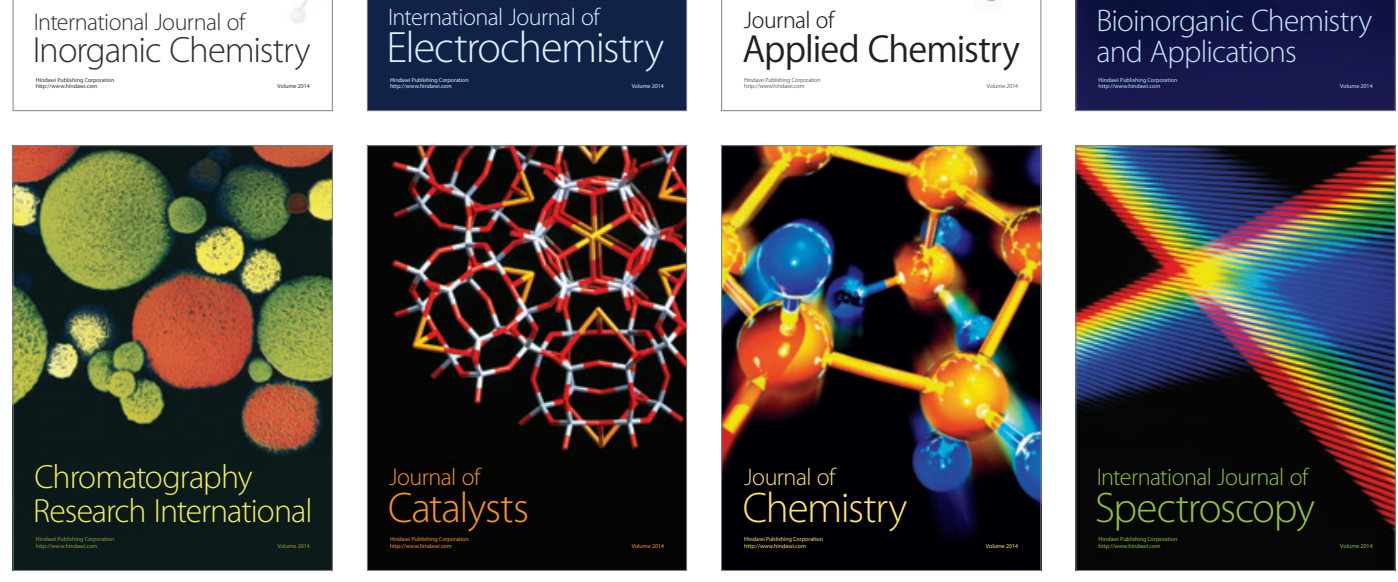